Portland State University

PDXScholar

3-11-2019

\title{
The Infrastructural Function: A Relational Theory of Infrastructure for Writing Studies
}

Sarah Read

Portland State University, read3@pdx.edu

Follow this and additional works at: https://pdxscholar.library.pdx.edu/eng_fac

Part of the Educational Methods Commons, and the English Language and Literature Commons Let us know how access to this document benefits you.

\section{Citation Details}

Published as: Read, S. (2019). The infrastructural function: A relational theory of infrastructure for writing studies. Journal of Business and Technical Communication, 33(3), 233-267.

This Post-Print is brought to you for free and open access. It has been accepted for inclusion in English Faculty Publications and Presentations by an authorized administrator of PDXScholar. Please contact us if we can make this document more accessible: pdxscholar@pdx.edu. 
The Infrastructural Function: A Relational Theory of Infrastructure for Writing studies

Sarah Read

Portland State University 


\begin{abstract}
This article theorizes the term infrastructure as a framework for articulating how writing products, activities, and processes underwrite organizational life in technical organizations. While this term has appeared broadly in writing studies scholarship, it has not been systematically theorized there as it has been in other fields such as economics, computing, and information science. This article argues for a fourpart framework that incorporates and builds on Star and Ruhleder's relational theory of infrastructure. Field work from a federally funded supercomputing center for scientific research operationalizes the theory for its contributions to writing studies scholarship and its applications for industry and writing pedagogy.
\end{abstract}

Keywords

Rhetorical Theory, Rhetorical Genre Theory, Actor Network Theory, Writing in Technical Organizations, Field Research, Infrastructure, Pedagogy 
Infrastructure is one of those really, really, really loaded words....If I were to try to explain what I think of as infrastructure like I was speaking to a 5-year-old, it would be all the things we depend upon but do not think about.... [There is also] this entire web of documentation and standards documents...that makes it actually possible [emphasis added] to use the machine.

What does the word infrastructure mean? And how does it relate to "this entire web of documentation and standards documents?" In this quote, a software engineer who works at the research facility where I did field work from 2014 through 2016, acknowledges the troublesome nature of the term infrastructure. But the engineer, who is close to the operations of the world's fifth fastest supercomputer (when it first came online in 2012), also acknowledges the centrality of software documentation, such as internal wikis, readme files, changelogs, and IBM Redbooks —"all the things we depend upon but do not think about"to the operations of the machine. He even says that these documents make it "possible to use the machine". In other words, writing has an infrastructural function for his work.

If a software engineer can unequivocally identify computer documentation as explicitly infrastructural to his work, then, in one sense, I have already articulated the infrastructural function for writing in the organizational life of the supercomputing center, and possibly for organizational life in general. In another sense, however, all I have done is identify the problem: What does the "really, really, really loaded word" infrastructure actually mean when it is applied to writing? While writing studies researchers (e.g., Grabill, 2010; Hart-Davidson et. al., 2007; Swarts, 2010; Vee, 2013) have already adopted this useful term from scholarship in other fields, including computer science and information systems, the term has not been fully theorized as to how it is applied to writing. As such, the term has had fluid application in writing studies scholarship and been taken up for opportunistic rather than strategic theoretical purposes. Scholarship, however, does seem to broadly acknowledge that writing, understood as a process, an activity, and as a product, has an infrastructural function: Now is the time to work 
through what that really means. In this article, I theorize an infrastructural function for writing as a framework and a methodology (or approach to research) for uncovering how writing, writing products, and writing processes underwrite organizational life, particularly in technical organizations.

I build on a thread of research in writing studies that documents the many functions of writing in the workplace and industry (e.g., Berkenkotter, 2001; Freedman \& Smart, 1997; Orlikowski \& Yates, 1994; Smart, 2006; Spinuzzi, 2003; Winsor, 1999). This thread was launched by Paradis, Dobrin, and Miller's (1985) groundbreaking ethnographic research about writing in a research and development division at Exxon. Primarily, their research aimed to make traditionally invisible work visible and relevant to the work of the employees and the organization: "Written communication takes up a considerable part of the industrial employee's time. ... Yet in-house writing and editing remain hidden activities in industry: As the saying goes, they just get done', (p. 281). Paradis et. al.'s research is the first study to document functions for writing beyond that of communication, or "information transfer" (p. 288). These functions included establishing accountability, managing employees and work processes and strengthening the social network.

Within this same thread of scholarship, a collection of essays (Bazerman \& Paradis, 1991) began the work to make professional and technical writing more visible by developing a vocabulary for articulating new functions for writing. In their introduction to this collection, the editors made clear their purpose to establish the texts of the workplace- "be it academic, white collar or blue collar"-as texts that have "had as great an impact on our modern culture and concepts of reality as the literary canon" (p. 4). Overall, they argued that texts constitute the professions.

Since the 1980s and 1990s, the heavy-hitting word constitute has carried a lot of freight for writing studies when it comes to articulating the functions of writing beyond that of communication, and information transfer in particular. The word enfolds a lot of rhetorical and discourse theory into a single term; however, the essential idea is that the process of writing many workplace texts is tantamount to not separate from the doing of those professions. For example, the work of a tax accountant primarily 
comprises interpreting and composing texts, in fact, the products of such work work are texts that both "define and serve the needs of the tax accounting community" (Devitt, 1991, p. 339).

Overall, this thread of writing studies research counterpoints the more commonplace idea that the documents that communicate the work of the professions are secondary to the work. This research aimed to close the perceived separation between substantive action and the text by providing a vocabulary for making visible the multiple powerful functions of workplace texts. Much of this research developed Miller's (1984) notion of "genres as social action," which established genre as an analytical category capable of incorporating the formal, rhetorical, linguistic, and pragmatic aspects of a text. For example, Winsor (2003) traced how new engineering knowledge, produced as multiple genres of documents (budgets, engineering diagrams, testing orders and reports, presentations, etc.), circulate up and down the hierarchy of a traditional engineering firm.

While this thread of scholarship has made great gains in documenting the functions of writing in the professions and organizations, it has had little reach outside of writing studies, especially in terms of affecting professionals' understanding of how writing relates to their professions. Almost anyone, if asked, will be able to tell you that workplace writing "communicates;" but I challenge you to find a nonwriting studies researcher who will tell you that workplace writing "constitutes." The gap in the knowledge about writing that is conventionally construed by these two terms, I believe, has consequences for how workplace writing is valued in workplaces and taught in classrooms. The software engineer in the epigraph might be an exception in spirit, but the term infrastructure is well developed within computing fields, so this software engineer can draw analogously on the term as it is understood in his field to include the facets of his job that he identifies as writing. In fact, this analogic thinking has worked both ways: Writing studies research has also drawn on meanings of the term infrastructure from computing fields such as information technology and information science and applied them to writing. This relationship is understandable because computing and writing studies share some proximity via the technologies (software, networks, computer hardware) that mediate them. This overlapping interest 
suggests that articulating writing as constitutive of organizational practices, culture, structures, and knowledge with notions of infrastructure from computing (and other fields) might provide a vehicle for writing studies researchers to more widely disseminate this theory of writing beyond scholarly forums.

At the theoretical level, this article articulates the term infrastructure by connecting existing definitions and uses of the term infrastructure in fields outside of writing studies with existing theory, particularly rhetorical genre studies (RGS). At the practical level, this article draws on artifacts and interviews gathered during field work at a supercomputing center to operationalize the theoretical arguments. Specifically, after describing my method for this study, I will review what infrastructure has meant in the fields of economics, informational technology, and information science and how the term has been taken up in writing studies research. Then, I propose a four-part framework for articulating what infrastructural means within writing studies. In explaining each element of the framework, I use field work on technical reporting and documentation processes from the supercomputing center to operationalize the theory and demonstrate the framework's utility for writing researchers and facility staff. Finally, I discuss the implications of this theory for writing studies researchers, teachers, and students of technical and professional writing, professionals who write in industry, and the broader public. Overall, theorizing the infrastructural function of writing serves four purposes:

1. To account for the axioms and objects of study that interest writing studies researchers

2. To point the way to pedagogical practices that will improve the teaching of technical writing to future professionals who write

3. To offer technical communication practitioners a tool to make tacitly held knowledge about organizational writing practices available for strategic decision making

4. To provide a conceptual foundation for revealing the structures and controversies that shape the operations of organizations in industry and government that affect citizens' daily lives. 
Method

Similar to my previous work about theory in technical communication (Read, 2015; Read, 2016; Read \& Swarts, 2015), this article is theory driven because it is the product of a methodology through which insight is gleaned inductively from experiences, interviews, and artifacts gathered during fieldwork. I understand theory development as a process of articulation and operationalization via field experience during which the researcher's specialized training is dialogically engaged with the voices and artifacts gathered at the field site. The product of this theory-making process is not a model that reflects an existent reality at the field site; rather, it is a theoretical tool to help researchers, practitioners, and teachers translate professional knowledge - in which expertise about writing is often only tacitly known and practiced - into a generalizable theory about writing that can apply across contexts. Thus, the product of field research is "something made" (Geertz, 1973), in the positive sense of creating fictions that contain insights that aid the understanding of individual experience without claiming to represent any given individual or organization exactly. This dialogic approach is especially salient in a dual-sided field such as technical communication, in which theory and application develop interdependently through the work of scholars and practitioners.

I gathered the field material in this article during site research from 2014-2016 with the approval of the internal review board at DePaul University (Research Protocol \#SR062314LAS-C1). From July 2015-July 2016 I held the position of guest faculty researcher at the national laboratory where I did field research. During the period of fieldwork, I interviewed 25 facility staff, gathered and catalogued over 500 pages of documents and I logged more than 100 hours of on-site informal observation, most of the time sitting in a cubicle in a large open office space waiting to interview staff or attend meetings while the activity of the supercomputing center went on around me (mostly that of knowledge workers sitting at computers). 
The site was a federally funded supercomputing center near Chicago, Illinois, that serves scientists from around the world. Its mission is to develop and operate supercomputers that can process enormous sets of data as efficiently as possible. Scientists are granted time on the supercomputer to process data to develop models of scientific phenomena, such as climate, air turbulence over an aircraft wing and the flow patterns of a new more environmentally friendly form of concrete. Around 85 staff members work at the facility and their functions range from the strategic and political work of the director and senior management to that of the daily maintenance of the machine and its supporting systems. With only a few exceptions of the administrative support and the facilities maintenance staff, the supercomputing center staff all have specialized training in high performance computing.

What Is Infrastructure?

The most common notion of infrastructure as material foundation comes from the Latin root infra, which means below. Most contemporary discourse defines it as "the underlying foundation or basic framework (as of a system or an organization)" (“Infrastructure," n.d.). In public discourse, this underlying foundation normally refers to material aspects of civil engineering, such as roads and bridges. In workplace discourse, it often refers to material aspects of information technology, such as hardware, software, and networks. Infrastructure, however, has also been developed as a theoretical construct in fields such as economics, information technology, and information science. Building on these constructs from other fields, writing studies scholars (e.g., Grabill, 2010; Hart-Davidson et. al., 2007; Swarts, 2010; Vee, 2013) have imported the term into their scholarship to ascribe certain characteristics to writing processes, technologies, and products. Writing studies scholars, however, have not yet systematized what infrastructure means for writing in particular. 
I will review what the term has meant in economics and computing before I review its appearance in writing studies scholarship because what the term has meant in writing studies so far has largely depended on its development in these other fields.

What Is Infrastructure in Economics?

Because the common notion of infrastructure is so strongly associated with the economy, it is useful to see how economists have developed the term. In economics, it has generally meant something close to the common definition: "the necessary economic and organizational foundation of a highly developed economy (transport network, labor force, etc.)" (Buhr, 2003, p. 2). But economic theorists have acknowledged that this definition, even when expressed in more nuanced ways, has not been sufficient for incorporating contemporary theories of economics, especially theories of dynamic economic development. To make the term more responsive to economic theory, Buhr argued it must be construed beyond the material instantiations of large public-works projects to include institutional and personal infrastructure and how those two infrastructures are in relation to each other and to economic development as a whole.

To develop the term, Buhr proposed replacing the common material definition of infrastructure with a functional one, a move that we will see repeated in computing and information technology (IT) as well. A functional understanding of infrastructure in economics means that what counts as infrastructure is determined not by what kind of thing something is but by what it does for the economy. Buhr's rather abstract suggestion of what infrastructure does is to "activat[e] or mobiliz[e] the economic agents' potentialities" (p. 15). For example, in the case of material infrastructure, roads are capital goods that make possible the movement of people and goods according to the goals of the economic agents, such as companies or states. A more inclusive definition also refers to information, including all of the relevant economic data, such as rules, stocks, and measures that function to mobilize "the economic potentialities 
of economic agents" (p. 16). In other words, a more expansive term in economics would include all infrastructures - including material, institutional, or personal (or human) — that promote the interests of economic agents.

What is Infrastructure in Computing?

As in economics, the theoretical move to broaden the definition of infrastructure beyond the material realm to one that accounts for its relational, social, and functional aspects is underway in computing and the allied fields of social and cultural anthropology of computing and interaction design. Certainly, infrastructure has largely referred to components that would qualify within the common definition of an underlying foundation or basic framework that is either virtual or physical. For example, virtual infrastructures include a software framework that implements cloud computing services (Araujo, et. al., 2014) and one for Web-based, computer-assisted learning that is a "technical foundation [XML-based] on which [computer-assisted assessment] tools may be written" (Joy et. al., 2002). Information technology (IT) also has multiple ways to refer to an infrastructure, ways that distinguish types of infrastructures by their function, context of use, the nature of their design, or how they are managed by system administrators. Some examples of IT infrastructures are immutable, composable, dynamic, critical, contact-center, cloud, cloud-storage and dark (undocumented elements of a framework) infrastructures (Rouse, n.d.). Physical infrastructures in computing comprise both data centers and the Internet and can include components such as power and cooling systems that enable large rooms of machines to run reliably and transmission media and network components such as cables, satellites, antennas and routers that enable communication between elements of the network.

Research in fields allied with computing, such as the sociology and cultural anthropology of computing and interaction design, has broadened our understanding of computing infrastructures to account for these fields' focus on the use of computing systems and how the systems affect users' or 
communities' behaviors. These notions of infrastructure incorporate social and human dimensions. Infrastructure in this sense is continuous with the social: As McCullough (2004) explained, "The role of computing has changed. Information technology has become ambient social infrastructure. This allies it with architecture. No longer just made of objects, computing now consists of situations" (p. 21). Overall, McCullough argued for a design philosophy that accounts for the fact that as computing becomes pervasive, ubiquitous, and part of the social infrastructure, the development and design of computing technologies must become human centered and mimic biological systems.

Computer scientist Dourish and cultural anthropologist Bell (2011) further developed the notion of information technology (IT) as ambient social infrastructure in their study of ubiquitous computing, or ubicomp. Similar to the functional definition of infrastructure developed for economics, the understanding that they gleaned from this qualitative study was that infrastructures, such as elements of the built environment, are "platforms for people to achieve their own individual goals" (p. 95). But in their effort to distract from the attention paid to conventional forms of computing infrastructure and develop the concept in a new way, Dourish and Bell argued for a notion of infrastructure that accounts for the social relations of space. They noted how metaphors in computing already invoke the spatial relations of computing experience, such as "informational super highway" and "virtual town hall" (p. 99). They also discussed the infrastructure of work spaces and home spaces - how they are negotiated via learned, familiar, and relational practices (p. 102). Ubicomp brings computing into spaces that are already populated and layered (p. 108), so to be successful, it must be interwoven into these spaces rather than applied on top of them.

What Has Infrastructure Meant in Writing Studies?

The term infrastructure is not new to writing studies scholarship. Technical communication and composition scholars have either anticipated or explicitly drawn on the material, functional, social, and 
relational notions of infrastructure as they have been articulated in economics and computing. Since the term has been used in scholarship either casually for its common place meanings or according to other fields' (such computing) theoretical entailments, the object of infrastructure in writing studies scholarship has varied depending on the study, and sometimes within the study. For example, Vee (2013) applied the term to the practices associated with literacy, which she understood as the successful use of technologymediated communication practices (e.g., symbolic writing systems or, more contemporarily, digital technologies) in order to navigate daily life. In Vee's work, literacy, technology and infrastructure enjoy a recursive definitional relationship that depend on their relationship to broader society.

Hart-Davidson, et. al. (2007) applied the material and social notions of infrastructure to writing practices in an organization. They developed the concept of infrastructure within the context of two case studies about content management $(\mathrm{CM})$ at nonprofit organizations, arguing for an approach to $\mathrm{CM}$ that is fully integrated with an organization's mission and organizational structure: CM as "a change in the technological and social infrastructure that makes their organization work" (p. 13). Later in the article, they referred to "network infrastructure" as the technological standards (e.g., internet file transfer protocols) that organizations rely on for content management. They also referred to infrastructure to as a holistic object that supports "user goals and actions" (p. 21) and, more specifically, as "organizational infrastructure" in regard to Web sites. While none of these more conventional uses of the term infrastructure is accompanied with a definition or a reference to sources in IT or information systems, the authors argued to rethink the relationship of technical communicators' writing practices by to the more conventional notions of infrastructure: "Writing is infrastructure, and thus it is both fundamental and invisible" (p. 32).

Another useful notion of infrastructure in writing studies scholarship is that of writing programs as infrastructure (Grabill, 2010). To ascribe infrastructural status to an organizational unit, such as a writing program, all of the various elements that make up a program collectively take on an infrastructural function — students, faculty, staff, curricula, classrooms, offices, technology, mission statements, syllabi 
and strategic plans. In addition, for Grabill, infrastructure "does work," (p. 15) (see also Grabill, 2007; Read, 2015), which means that an assemblage of people, things, technology, and documents cannot be considered infrastructural until what it is infrastructural to can be identified - the assemblage must do something. Within this understanding of infrastructure as emergent, what counts as infrastructure is determined based on its real-time outcomes rather than on the existence of a static collection of familiarly infrastructural objects. In other words, a bridge to nowhere does not count as infrastructure.

Grabill's (2010) discussion of infrastructure as functional and relational is useful for how it abstracts the term infrastructure to the programmatic, or organizational, level. So, if writing - as an activity (e.g., composing) or process (e.g., document cycling) and also as a product (e.g., a document) can be infrastructural to organizational life, so can administrative entities, such as writing programs. For example, Grabill suggested that writing programs are better than academic departments at doing community outreach work because their value and work-practices systems reward collective rather than just individual work. These systems, Grabill argued, emerge from the unique relationships between the various human and nonhuman actors of a writing program (e.g., the program's faculty, students, curriculum, mission, access to classrooms and technology) and the program's relationship with the university as a whole. Further, it is because of these unique relationships between human and nonhuman actors - their unique brand of "crystallization of institutional relations" (Dourish \& Bell, 2011, pp. 9697) - that writing programs can function as effective infrastructures for community outreach work. In other words, these actors function collectively as a network across which the work of an organization "can be both distributed and coordinated" (Swarts, 2010, p. 132).

Grabill's (2010) understanding of infrastructure is, like that of Dourish and Bell (2011) and Swarts (2010), defined in terms of the relationships between material and nonmaterial objects, or actors, including humans as well as technical, social and cultural objects, norms and standards. This relational theory of infrastructure is founded on Star and Ruhleder's (1996) theory of a relational understanding of infrastructure grounded in actor-network theory (ANT). The scholarship reviewed in this section sets the 
foundation for a more developed relational theory of infrastructure for writing studies, as I will be developing here.

\section{Star's Relational Definition of Infrastructure}

Perspectives in scholarship on infrastructure that exceed the material to include functional and relational notions either cite directly or anticipate Star and Ruhleder's (1996) and Bowker and Star's (1999) development of infrastructure as a relational concept within the ontology of ANT. Fundamentally, a relational definition of infrastructure means that infrastructure is only infrastructure when it serves an infrastructural function. In other words, infrastructure is not built to be infrastructure; it only becomes infrastructure when it achieves certain functions for an individual's or organization's work practices. Star and her collaborators developed this theory when documenting the impact that information standards have on individuals or the experience of everyday life. For example, Lampland and Star (2009) edited a collection of case studies of standards and how those standards have "contained messy reality" (p.11). Infrastructural information standards might be as small as the irritating necessity to have to enter a phone number into a computer-based form in order for the form to be considered complete. On the other hand, such standards might be as catastrophic for individuals and society as the standards for determining a person's race.

Star and Ruhleder (1996) developed the meaning of infrastructure as a relational concept that includes, but also succeeds, the commonplace material notion by basing their framework on ANT (see also Star, 1995; Bowker, 1994; Bowker \& Star, 1999). This posthumanist perspective affords a shift in the focus of a study from objects and people to the relationships between objects and people (or actors). As an ontological proposition, ANT establishes continuity, rather than division, between technical and social actors (e.g., computers, people, and information standards) and, with the principle of symmetry, assigns agency to nonhuman actors (the most infamous case is that of a door closer in Latour, 1995). For 
example, within an ANT framework, the electricity delivered to a home to run the dishwasher is coconstitutive of the power plant that produces it. The existence of the power plant depends on the homeowner's need for electricity to run the dishwasher just as much as the homeowner depends on the existence of the power plant to produce electricity. All are actors — both human and nonhuman —allied in a network to enact domestic electrical use. But a study based in ANT can become the study of everything all at once, a proposition that does not help to clarify, in a practical sense, what the object of study is in a study of infrastructure.

The lack of clarity around what counts as infrastructure has not gone unnoticed in computing. If infrastructure is not limited to material technical structures (e.g., bridges, roads, and networked computers) that can be seen and counted, then what exactly is the nature of infrastructure — does it include everything? Bygstad (2008) raised this question in order to critique what he saw as the ontological fuzziness that results from Star and her colleagues' foundation of infrastructure in ANT. Bygstad's critical realist viewpoint undoes the basic premise of ANT by reprivileging human activity and agency and separating the structure and the action of a sociotechnical network into the study of two separate but "dynamically linked" (p. 3) sociotechnical networks. While there are intuitive and practical reasons for Bygstad's viewpoint, I will build on Star's framework and argue how the affordances that ANT lends to a theory of infrastructure remain valuable.

Star and Ruhleder (1996) develop eight elements that ascribe certain characteristics to infrastructure, such as its invisibility due to its embeddedness in tacit practices and its recursive relationship with a community's conventions of practice. Most radically, the ontology of ANT enables a view toward infrastructure that dissolves the boundaries between its human, cultural, technological, and other material components. Their eight "dimensions" from which infrastructure emerges (p. 113) are the following:

1. Embeddedness: Infrastructure is sunk into other structures, social arrangements, and technologies. 
2. Transparency: Infrastructure invisibly supports tasks - it is incorporated into tacit practices.

3. Broad reach or scope: Infrastructure has reach beyond a single event or practice.

4. Learned as a part of membership: Newcomers learn to use infrastructure in becoming members of the community.

5. Links with conventions of practice: Infrastructure both shapes and is shaped by the conventions of a community of practice.

6. Embodiment of standards: Infrastructure takes on transparency by plugging into other infrastructures in a standardized fashion.

7. Built on an installed base: Infrastructure is built on existing structures and inherits their strengths and limitations. It is fixed in modular increments, not all at once or globally (see also Bowker \& Star, 1999, p. 35)

8. Becomes visible upon breakdown: Infrastructure is most noticeable when it breaks or disrupts work.

Given these elements of infrastructure, it is important to remember that, overall, a relational theory of infrastructure depends less on the material properties of an infrastructural object, such as the large size of a bridge or a feature-rich learning management system (LMS) than on whether it serves an infrastructural function for the community that built and uses it (i.e., even the biggest bridge to nowhere is not infrastructural; an LMS is useless if instructors don not use it). But this move from a material to a relational understanding of infrastructure might seem unnecessarily confounding, especially given Bygstad's (2008) critical realist critique and the powerful metaphorical entailments of infrastructure as material objects that serve to support an economy or IT system. Despite these concerns, however, Star and her collaborators have strong reasons for basing their theory in ANT, primarily because ANT is 
uniquely suited to making visible the objects, relations, and phenomena that are normally invisible to everyday life.

For Star and her collaborators, the affordances of ANT that enable her imperative to make visible the "boring" things (Star, 1999; Star \& Ruhleder, 1996) that make life work. Far from being a disparaging word for labeling things of little value, the term boring, as Star (1999) used it, refers to the essential elements of the "ecolog[ies]" of the high-tech workplace, home, or school that "permeate all of [their] functions" (p. 379). These human and nonhuman elements—-such as information standards, design of computer networks, Internet protocols, domain names, and classification systems - tend to be invisible to the user of these systems because of how they are imbedded in daily, tacitly understood work practices. But their invisibility to those who are using information systems or living their everyday life does not mean that these standards and other infrastructural elements are free of controversy-quite the contrary. Star's wanted to develop a methodology for studying the boring and invisible infrastructure in order to bring to light these controversies that are otherwise "squirreled away" or "buried in inaccessible electronic code" (p. 378). And writing too, in its many forms, is often a "boring thing" that is embedded in work practices that are largely tacitly understood. Developing methodologies to make invisible writing visible enables us to make arguments for its value in scholarship, teaching, and industry.

While the motivation to make the invisible visible is usefully adopted for writing studies from Star \& Ruhleder's (1996) eight dimensions of infrastructure, their theory has been articulated to serve the study of information and standards - not writing, even broadly construed. Their eight dimensions are not sufficient for a comprehensive theory of infrastructure in writing studies because studies of information do not account for the processes that create or circulate the texts in which information is inscribed. In the following section I will develop four elements of a theory of the infrastructural function of writing.

Four Elements of a Relational Theory of The Infrastructural Function of Writing 
In developing four elements of a relational theory of the infrastructural function of writing, I derived one element (relationally defined) by consolidating the relevant dimensions of Star and Ruhleder's (1996) original eight dimensions of infrastructure. Then I created three additional elements (inclusiveness, alliance brokering, and mission critical) that build on precedents in writing studies scholarship and that foreground the unique concerns of the study of writing:

1. inclusiveness: a broad scope for what counts as writing

2. relationally defined: a focus on what writing does for something or someone (incorporates rhetorical genre theory)

3. alliance brokering: writing mediates essential alliances

4. mission critical: writing is essential to the operations of an organization

These four elements are not fully coequal in type or scope. While the first element, inclusiveness, is an axiom that has been articulated and developed in writing studies scholarship over the last 2 decades, the second and third elements, relationally defined and alliance brokering, are definitional of writing's infrastructural function. The fourth element, mission critical, serves as an umbrella term for the prior three elements: writing that functions infrastructurally is critical to an organization's overall mission. To persuasively argue that writing is mission critical requires documenting writing that might not be broadly recognized as writing, articulating how writing functions in relation to the organization and its operations, and documenting how writing products and processes broker essential alliances that sustain the organization. In this sense, the fourth element is both a methodology (an approach to research) for studying the infrastructural function of writing and a value proposition (writing is operationally critical) for writing in organizations, particularly for technical organizations.

Inclusiveness 
Inclusiveness means that what counts as writing is meant in the broadest possible terms. This inclusivity makes visible the types of writing that have essential functions for organizations but that might not be conventionally or culturally visible as writing. Recognizing that what people, including writing researchers, count as writing is often based on both explicit and tacit beliefs and practices about writing as it relates to their work or their experiences with school writing, contemporary writing researchers have aimed to broaden what counts as writing. Inclusiveness broadens both what counts as writing in the sense of formal features of a text and what counts as the writing process.

As a point of entry into the discussion about what counts as writing, here is a list of documents (in alphabetical order) that I either collected or viewed during fieldwork at the supercomputing center:

- computer programming libraries

- $\quad$ project management plan for the cross-cutting Operational Annual Review (OAR) report

- director's response to recommendations of operational review committee

- e-mail of job failure analysis (JFA) data

- federal funder guidance and template for current year OAR report

- financial models of the lease terms

- graphs of machine availability and down time

- maintenance contract with machine vendor

- office white board notes

- OAR report, print, PDF and Powerpoint versions

- $\quad$ output of a script to code job and system interrupts

- press releases to the public or media

- $\quad$ project management software interfaces (e.g., Oracle's Primavera)

- public-facing annual reports

- public-facing science brochure 
- public-facing Web sites

- $\quad$ scientific grand challenges reports and exascale review reports

- $\quad$ scientific articles and other science products generated by users

- $\quad$ software documentation (Internal Wiki, Read-Me Files, Changelogs, IBM Redbooks)

- $\quad$ sticky notes on office doors and white boards

- $\quad$ supercomputer machine leases

- user agreements

- visualization of machine voltage over time

As a thought experiment, consider which of these documents would count as writing to a writing studies researcher, an introductory technical writing student, a literature student in our classrooms, or to an administrative assistant, a software engineer, or a media and publicity specialist at the supercomputing center? Would most of us agree that a 126-page bound, glossy OAR report counts as writing (see Figure 1)? But would we count an output of a script to code job and system interrupts as writing (see Figure 2)? This question would likely raise debates overs issues such as authorship, medium, composition, and language use. The element of inclusiveness acknowledges that even though these documents, as genres, are distinct in form, content, linguistic conventions and rhetorical exigence, both documents count as writing that can have an infrastructural function for the operations of the supercomputing center. 


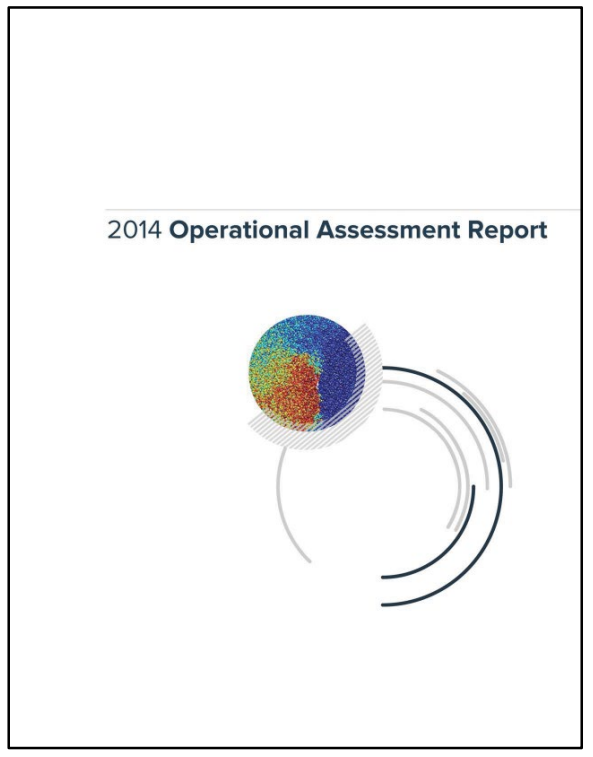

Figure 1. Cover of the 126-page Operational Assessment Review Report. This report includes a table that summarizes the performance of the machine over the course of a year. The annual metrics reported in this table are the products of daily machine-operations reporting, such as the script output excerpt in Figure 2. Courtesy of Argonne Leadership Computing Facility. 


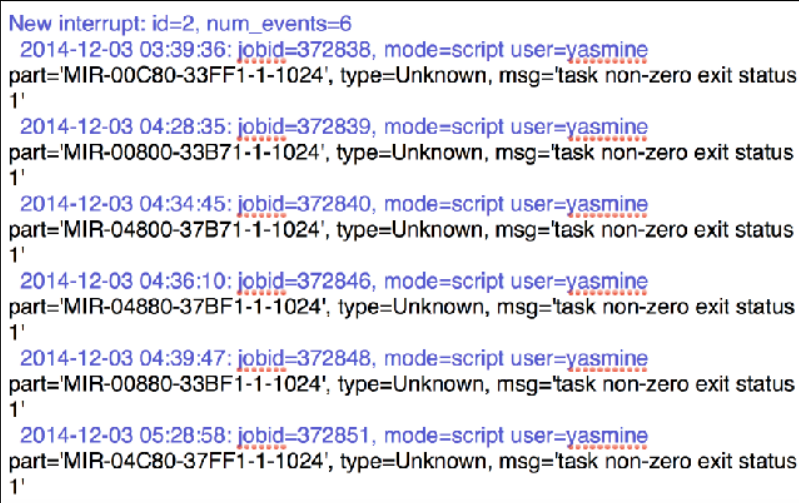

Figure 2. Excerpt of a script output for a job failure analysis. Data on intemutions to the machine

operations are collected and interpreted on a weekly basis by the cperations team. These data are

ultimately processed into ammal metrics that are reported in the ammul Operational Assessment Report

(see Figure 1). Courtesy of Argonne Leadership Computing Facility. 
The study of writing in professional contexts, particularly in technical organizations, by scholars who are grounded in the humanities can be limited by a restricted notion of what counts as a text—unless what counts as a text is explicitly broadened. Dorothy Winsor $(1992,1994)$, during her more than 20 years of studying writing in engineering environments, argued multiple times that writing studies scholars would be limited in their ability to understand the writing processes in technical organizations until they broadened their conception of writing to include texts that do not include words or require the direct presence of a human being and that are not products of the free creation of meaning (Winsor, 1992). These characteristics of many texts in technical environments challenge ideological assumptions that have long defined for both scholars and the general public what counts as writing. In supercomputing center, Winsor's broadened view of writing incorporates many of the documents I listed. For example, several documents, such as user agreements and machine leases, are boilerplated and require little new or original writing.

The element of inclusiveness also incorporates Latour and Woolgar's (1986) notion of inscription into what counts as writing. Inscription is most easily understood as "the conversion of physical reality into written documents"' (Winsor, 1990, p. 60). In their study of scientists at work, Latour and Woolgar documented how they used laboratory instruments to write down the forces of nature and then drafted and circulated among their peers the interpretations of what these inscriptions mean. These interpretations were successively refined via the resolution of controversies until a stabilized version, often in the form of a scientific research article, was finally published. Over time, their new scientific claim lost its mantle of uncertainty and was admitted as new scientific knowledge independent of the controversies that shaped it.

For a theory of the infrastructural function of writing, the notion of inscription incorporates much of the writing that is produced by software, machines, and other technology, such as in Figure 2. This machine-produced writing lets human beings in on what is going on at a scale and speed that often 
exceeds human perception. For example, this notion is especially salient to the operations team that oversees the running of the supercomputer. They must make decisions about the machine's operations based on inscriptions created by the machine itself that are outside the scale of human capability (see Figure 2). The supercomputer's unique architecture incorporates technology called the control-database system that explicitly functions to monitor and report the operations of the machine at the level of each of the 49,152 compute nodes.

Like Latour and Woolgar's (1986) scientists, the operations team must interpret these inscriptions in order to make defensible decisions about machine operations. Ultimately, the interpretations of these inscriptions are composed into formal written reports, such as the OAR report (see Figure 1), that are circulated to external stakeholders, such as the supercomputing facility's funding agency. While the annually produced OAR report is a more conventional and widely circulated product of writing than are the inscriptions produced by the machine, the work of interpreting the machine's inscriptions shapes the hourly, daily, and weekly work activities of the operations team. By incorporating the operations team's writing practices of interpreting the machine's inscriptions into a conventional document-cycling model focused on drafting and editing, we can account for how the writing activities involved in producing the OAR report sustain the normal operations of the machine (Read \& Papka, 2016).

\section{Relationally Defined}

Relationally defined means that the infrastructural function of writing is defined by what writing does for something or someone rather than by the formal characteristics (e.g., length, content, linguistic features) of any given document or writing activity. To put it another way, just as a huge bridge to nowhere has no infrastructural function for an economy or for a local population, a writing product or activity — no matter how well written or well executed-has no infrastructural function if it does not underwrite the operations 
of an organization. The infrastructural function, then, must be able to identify for what or whom the writing functions as infrastructural.

The relationally defined element consolidates Star and Ruhleder's (1996) eight dimensions outlining a relational theory of infrastructure for information and standards in order to further develop the existing writing studies theory. Common to many of the original eight dimensions is the notion that information and standards are not separate from other practices and structures of the system but are embedded (dimension 1) or embodied (dimension 6) within them. Likewise, in writing studies, existing theory accounts for how texts and writing practices are constitutive of the social practices and structures of a community or an organization (see Giddens, 1984) and therefore are not separate from them. Bowker and Star (1999) expressed this same sentiment about information and standards when they suggested that infrastructural elements are "not accidental, but constitutive" (p. 36).

This relational approach to the study of writing in organizations has been most fully developed in rhetorical genre studies (RGS) by using genre as the analytical unit of analysis. Much of the writing studies scholarship that I have cited in this article (e.g., Bazerman \& Paradis, 1991; Berkenkotter, 2001; Winsor, 2003) is underwritten by genre study. Since the 1980s, this thread of scholarship has developed a notion of genre that is rooted in sociological and cognitive perspectives for understanding the relationships between texts, social and organizational structures and rhetorical situations, (see Bawarshi \& Reiff, 2010, Chapter 6). Key tenets of RGS maintain that genre is a concept marked by stability and change; genre functions as a form of situated cognition; genre is tied to ideology, power, and social actions and relations; and genre recursively helps to enact and reproduce community (Bawarshi \& Reiff, 2010, p. 82). Overall, these four tenets are based on the fundamental idea of defining a genre via its recurring "social action" (Miller 1984, 2015), rather than on a list of a text type's characteristic features or its place in a taxonomy of related texts.

This move to define genre or any generic text via its social action is another way to understand 
the relationally defined element in regard to the infrastructural function of writing - genre as social action is just another way of defining for what or whom writing functions as infrastructure. To function as infrastructure, genres, like bridges, must do more than simply exist, they must do something meaningful for the people or organizations relying on them. Within RGS, a recurring text does not constitute a genre if the community that creates and uses it cannot agree on its function or whether that function is successful. For example, Miller (2015) recalled how she raised the question about whether environmental impact statements qualify as a genre. Certainly, as a text type they have recognizable and stable features, but she found that the community that creates and uses these documents could not agree on their use or whether they made a difference.

In addition to the useful agreements between Star and Ruhleder's (1996) eight dimensions of infrastructure and rhetorical genre theory, elements of ANT also shape a relational understanding of infrastructure. In short, ANT's ontology of symmetry between human and nonhuman actors expands the scope of what and whom writing can function for as infrastructure. But, while RGS is a social theory and assumes that that the functions of any given genre are defined by the social contexts of its creation (the creators) and use (the users), ANT does not make this same assumption. As a postsocial or posthumanist theory, ANT can define functions for genres or documents based on the outcomes that they enact for the network as a collective agent. For example, from an ANT view point, a researcher might document a function that a genre has for an organization that is independent of how individual staff members or the organization's culture define that genre. This view opens the door for a researcher to collect data and produce an account of an organizational writing process that consolidates the views of all human and nonhuman actors into a single account (Read, 2018).

For example, at the supercomputing center, the OAR report (see Figure 1), an annually produced document that reports to the funder in Washington DC on the operational performance of the supercomputer, can be seen as having multiple infrastructural functions for the facility, depending on the 
view points from which its functions are understood. From the view point of the many facility staff involved in composing the report (the social view), it has a rhetorical purpose that serves "as a statement [to the funder] of who we are, what we've done" or as an "intragroup tool for communication" that spreads organizational knowledge across the center's various working groups. Another staff member described the purpose of the report as "tell[ing] the world how great the facility is really.... It's to showcase what we've done, to highlight the science that's been done, to show how well the machine has been operated throughout the year and to really pat ourselves on the back." These understandings of the report's rhetorical purpose for the organization are not unexpected, especially since they are founded on the conventional understanding that reporting documents are tools for the transactional communication of information. But, the understandings are limited by the rhetorical triangle of message-author-audience so they do not account for the report's functions the has outside of this framework. As a result, they offer little new insight for either staff members or the writing researcher. An ANT perspective, however, might look at, for example, how the report functions in relation to the supercomputing machine, the airconditioned hallways of the funder's offices in Washington, DC, or the entire network of actors that enact the supercomputer's operations.

Using ANT to view the OAR report's function broadens our understanding of what and who the report functions for and thus contributes new understanding to the processes required to compose it. If the report is understood as an inscription, or trace, of the network of human and nonhuman actors that enacts the supercomputing center, then it can function as a substitute for this network. Because a warehousesized supercomputer and its staff cannot travel to Washington, DC, the supercomputing center must send a more reasonably sized substitute. Latour (1990/2011) understood an unchanging and moveable form of an object that substituted for the real thing to be an "immutable mobile" (p. 26). Often an immutable mobile takes the form of a document because it is well suited for travel and can efficiently contain a fixed representation of an otherwise changeable object. 
If the OAR report is understood as a comprehensive account of the network of which the supercomputing center is an outcome, then the OAR's composition process becomes one of gathering and writing down all of the actors (human and nonhuman) that are essential to its operation. This process requires more than just asking the director of the facility for his view point, which is limited by his position in the organization, as is the case for any given staff member. It also requires, for example, giving the supercomputer itself ways to speak by collecting and interpreting data about its operation (see Figure 2). In fact, many of those processes for "writing down the machine" (Read, 2018) are already in place to support the OAR report's development because most of the work of writing down the machine's operations are not considered by staff to be part of the composition process of the report. Accounting for this work as part of the composition process makes visible how the OAR reporting process is not separate from the daily operations of the machine. This view could change the value that staff members place on the reporting process as well as their understanding of their role in it.

Casting the OAR report's composition process as writing down the network draws on language and concepts that are supplied by the researcher rather than the research participants. Not surprisingly, individual staff members are not likely to use phrases such as a trace of all the actors or an immutable mobile when asked to name the function of the report. But despite the arguably abstruse language that ANT draws on, such a perspective of the report's function can show staff how no single stakeholder in the complicated reporting process has a comprehensive view of the report's purpose and function for the facility. This realization forms a foundation for more critical dialogue about its value and opens up avenues for streamlining the report's composition process. Theoretically, rather than socially, defined functions for writing and writing processes also serve a useful purpose for understanding the overall function and value of the report to the facility.

Thus, the relationally defined element of a relational theory of the infrastructural function of writing encompasses two aspects: a focus on what writing products or processes do for something or 
someone and the understanding that what writing does is embedded in, maintains, and reproduces the social and material practices and structures of an organization. These two aspects proceed from the theory traditions of RGS in writing studies and ANT (e.g., Latour, 2005) as developed by Star and her colleagues for the study of information standards.

\section{Alliance Brokering}

Alliance brokering means that infrastructural writing products and processes mediate alliances with actors that are essential to an organization's existence and operations. In keeping with the posthumanist perspective of ANT, these alliances are not always with actors that are human. Likewise, these alliances are also not always with the audiences of the document's rhetorical message. For example, a negotiated contract with the power company signed by human representatives of the power company and the supercomputing center is not only a record of a transaction; it is also evidence of the alliance of a powerful actor with the facility: an economically feasible contracted price for electricity. Because operating the supercomputer requires so much electricity to it would not be economically viable to build or run the supercomputer without a negotiated price. In this sense, both the process of negotiation and the final contractual document are infrastructural to the building and operation of the machine because they are part of the "stable arrays or networks of relations" (Law, 2002, p. 91 cited in Read \& Swarts, 2015) that enact outcomes, such as the building and operating of the supercomputing center. Alliance brokering recognizes that no organization exists in isolation and that organizations depend on negotiated alliances for their existence.

How writing products, activities, and processes mediate alliances with actors essential to the organization is informed by ANT's notion of translation. Latour's (2005) ontology of translation developed as a research tool for tracing (creating an account) of the rhetorical-political interdefinitions, or 
alliances, that induce two mediators, such as the power company (or the contracted price for electricity) and the supercomputer (and its dependence on electricity to run), to coexist (p. 108; see also Spinuzzi, 2008). Writing, writers, and writing products have a specialized role in the network of relations that enact the world around us because of the mediatory function of language in negotiating rhetorical-political alliances between human and nonhuman network actors (Read \& Swarts, 2015, p. 15). This fact has not gone unnoticed by writing studies scholars who have theorized and documented how genres and assemblages of genres mediate collaborative, and often distributed, work in government and industry (e.g., Spinuzzi, 2002, 2004, 2008, 2010; Yates \& Orlikowski, 2002).

While language is not essential to interdefinition and alliance building, especially in the natural world — neither Callon's (1986) famous scallops nor Latour's infamous door closer (Star, 1995) speakbuilding and maintaining complex human-built technologies and institutions require collecting, interpretating, inscribing, exchanging and archiving data and information: In other words, the mediatory function of writing is infrastructural. At the supercomputing center, mediation is largely the outcome of the knowledge work done by administrators, accountants, software engineers, the operations team, procurement specialists and many others in specialized roles unique to high performance computing. But the work of mediation is also done by the supercomputing machine as it monitors its own operations and inscribes operational data that would otherwise be beyond human reach.

The OAR reporting process offers an example of how writing brokers alliances between the many human and nonhuman actors that sustain an organization. A primary rhetorical purpose of this process is reporting to the supercomputing center's federal agency funder on the machine's performance as compared to the operational metrics that were negotiated a year before. For example, one of these metrics is about the machine's "utilization," or the percentage of time that the system's computational nodes actually run user jobs. To remain in good standing with the funder, the facility must hit or exceed its operational metrics. Because failure is not an option, the year-long tasks of collecting and interpreting the 
operational data and composing the OAR report can be understood as a process of brokering alliances between three powerful actors: the funder, the operational metrics, and the supercomputing center. In other words, the end really does determine the means, which are mediated via the rhetorical-political process of defining, measuring, and reporting on the facility's operational metrics.

A large part of brokering the alliance with the funder is negotiating the operational metrics that the facility will be asked to meet and report on - this negotiation does not happen independently of the review and reporting process but is actually subsumed within it. Therefore, we must look beyond the final report to document how these alliances are brokered. In fact, it is an assemblage of genres that cycle annually (see Figure 3, Steps 1-6; Read \& Papka, 2014) that do the work of brokering these alliances. The collection and interpretation of the operational data, the reporting on the current year metrics, and the negotiation of the following year's metrics are genres the constitute a self-perpetuating annual cycle that initiates the next cycle of review when the Response to Recommendations (Step 6) is submitted to the funder. While the major OAR report (Step 3), a 126-page glossy publication that formally makes the facility's argument that it has "proudly met or exceeded all metrics set for the facility," is the most substantial and publicly circulated document, it is neither the beginning nor the end of the cycle. 


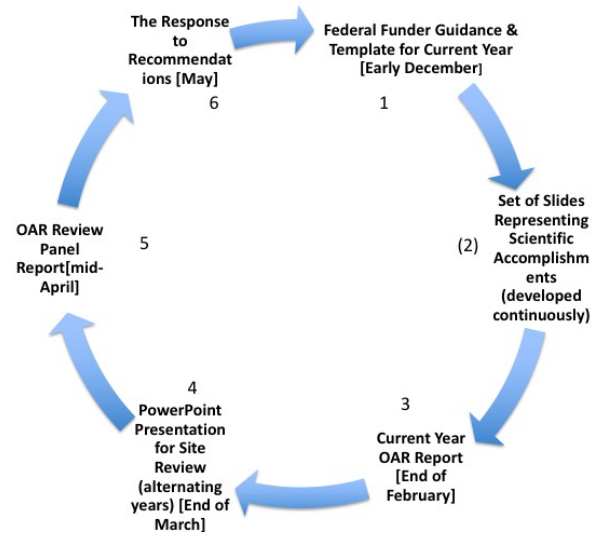

Figure 3. The annual operational assessment review process genre cycle 
Construing the OAR process as a genre cycle enables a view of the major OAR reporting document (see Figure 1) as just one step in the essential, dynamic process of brokering and negotiating an alliance with the funder. This view is in addition to the more conventionally understood (and socially defined) communicative function of a long, backwards-looking reporting document as an end in itself. Facility staff who are not involved in other steps of the genre cycle might be surprised that the reporting document is not the primary end (or outcome) of the review process because the composition, editing and production of this document consume a lot of staff time, and, the document itself is the most visible product of the OAR process. The fact that the formal report is not the primary end of the OAR process raises the question of whether the facility should invest so many resources in it if the genre cycle could continue brokering the essential alliances with a lesser effort. Part of the value of research that documents infrastructural writing processes in organizations is that it makes visible possible contradictions between the real functions that these processes have for organizations and how they are more broadly perceived and valued by senior management and the staff.

\section{Mission Critical}

The element of mission critical is both a methodology for uncovering the infrastructural function of writing in organizations and a value proposition for writing in organizations, particularly technical organizations. In other words, by documenting the interdependence of writing, technology, and politics (the methodology), we can see how infrastructural writing products and processes are not separate from an organization's normal operations, but constitutive of them (the value proposition).

As a methodology for uncovering the infrastructural function of writing, the mission critical element builds on a project that Bowker (1994), one of Star's frequent collaborators, called an “infrastructural inversion." This type of project aims to uncover systems that have "disappear[ed] almost 
by definition" (Bowker \& Star, 1999, p. 31), such as databases, standards, and technical networks. It involves "learning to look closely at technologies and arrangements that, by design and by habit, tend to fade into the woodwork (sometimes literally!)" (p. 34). For Bowker, an infrastructural inversion was a methodology for exposing the "depths of interdependence" (Bowker \& Star, p. 34) between information infrastructure, knowledge work, and politics.

Given the field case that I have developed here, I can argue that the OAR document and process are mission critical for the supercomputing facility because of the prior three elements (inclusiveness, relationally defined, alliance brokering). My argument depends on (a) an inclusive understanding of what counts as writing that comprises the collection and interpretation of the machine's inscriptions by the operations team; (b) a relational focus on what and who the writing functions for that includes nonrhetorically or socially defined beneficiaries, such as the supercomputing machine or an operational metric; and (c) an understanding that the writing process and product serve to broker the sustaining alliances between the federal funding agency, the operational metrics and the supercomputing center.

Thus, to argue that the OAR document and process are mission critical to the supercomputing center suggests a value proposition that, to be persuasive, requires the kind of data generated by the other three elements of my relational theory of writing's infrastructural function. Although writing researchers are already inclined to take this view based on theoretical arguments, such data are necessary to persuade industry stakeholders who invest time and other resources into the OAR document and process, often without complete knowledge of the outcomes that they have for the facility. When the researcher can present a full account to facility stakeholders from a collective, or network, view that is not otherwise available from the view point of any given staff member, facility staff can use this account for strategic purposes. In other words, in a field study, the contribution of the writing researcher is to gather data to make writing and writing processes visible to the industry stakeholders, who will ultimately decide on the value that a documentation process has for the facility and whether or how to make changes to it. 
Implications of a Relational Theory of Infrastructure for Writing Studies and Beyond

Infrastructure is a powerful metaphor for what writing is and does in organizational contexts. While commonplace entailments that connote the undergirding, substrate, or framework of a system are already useful for bringing attention and value to the less visible writing products and processes in organizations, theoretical development of the term as a relational concept broadens the scope of the metaphor to afford new understandings of writing not otherwise available. At the supercomputing center, the professionally produced, glossy metrics-reporting document that is the OAR report is, on the one hand, a conventional, backward-looking rhetorical product of an annual document-cycling process that includes multiple drafting rounds of composition, critique, and editing. On the other hand, when it is viewed from the view point of a relational theory of infrastructure for writing studies, additional functions of the document and process are revealed: The OAR process, when understood as inclusive of machine inscriptions and many other normally less visible and formal operational genres of writing, is both constitutive of facility operations and essential to maintaining alliances critical to the survival of the organization. Industry stakeholders can use this comprehensive understanding to make more informed strategic decisions about how to manage the reporting process.

One of the implications of my four-part framework for a relational theory of infrastructure for writing studies is that the notion of infrastructure need no longer be imported and adapted from other fields of study (e.g., economics, information science, information technology). Comprising four elements — inclusiveness, relationally defined, alliance brokering, and mission critical — this framework incorporates established theory of infrastructure from other fields and invents additional elements that specifically serve the study of writing. Now infrastructure can be incorporated into the writing studies canon of analytical terms alongside theoretically mature terms such as genre and rhetorical situation. An 
outcome along these lines would be the explicit inclusion of infrastructure in the next editions of the field's summary texts, such as those by Heilker and Vandenburg (2015) and Addler-Kassner and Wardle, (2015).

The work I have done to theorize infrastructure for writing studies also raises the possibility of a number of research questions. For example, what are the infrastructural functions for writing across organizational types and how might the elements of this theory be further developed to account for any variations? More broadly speaking, an extension of this theory would consider how the four elements account for writing that is not part of an organizational context: Can this theory account for creative writing or personal writing? Is it important that it does so? To launch the theory, I have purposefully kept its scope within an organizational contexts, and particularly that of technical organizations, where the stakes for extending the theory of writing are clear. But the theory's robustness might depend on its generalizability to account for the full breadth of writing activity.

Another unanswered question raised here involves the relationship of the infrastructural function of writing with the more established (in common discourse, standard technical and professional writing textbooks, and scholarship in general) function of writing to communicate: Does the infrastructural function of writing fully incorporate the communicative function of writing or vice versa? Since Paradis et. al.’s (1985) ethnographic study at Exxon, writing studies researchers have been looking beyond information transfer as the primary function of writing. But less clear is how the communicative function has been incorporated into subsequent theory: Are there infrastructural writing products, activities, or processes that do not also communicate, or is the reverse possible? This question has both pragmatic and theoretical implications that are far too complex to answer satisfactorily here. While theoretically the infrastructural and communicative functions of writing can be shown to converge, especially within a posthumanist-informed framework such as the one developed here, in the classroom and when working with industry stakeholders, it is likely easier and more useful to maintain both terms as complementary 
and overlapping, but independent concepts: Writing is infrastructural and communicative. Most students and workers already accept the importance of written communication to a successful organization and career. Given the powerful, commonplace metaphorical entailments of infrastructure, teachers and scholars have an opening to add depth and scope to existing understandings of the functions of writing.

In addition to providing the analytical work for writing researchers, my aim for this project has been to establish a framework for teachers to accelerate the learning of a more sophisticated understanding of the centrality that much of the writing activity of technical professional's has to their organization's operations and mission. One reason for the low visibility and poor understanding of the writing that technical professionals do is the lack of a framework and a methodology for teaching engineers, computer scientists, and other technical professionals-in-training how the writing that they do is mission critical to their organization. Seasoned professionals, such as the software engineer quoted in the epigraph, might understand how essential certain specialized types of writing are to their own work. But there is no reason why this view must be learned only through hard and long experience. For example, for classroom use, the mission critical methodology for documenting how writing is infrastructural can be adapted in order to prompt students to make visible and identify the infrastructural documents and writing activities within their fields of study (e.g., by interviewing professionals) or in their own work experiences.

The main implication of this article for industry stakeholders interested in improving organizational writing processes is that it provides a framework for making visible and imbuing value in the writing activities of staff members not normally considered to be writers in a conventional sense, such as the staff of the supercomputer's operations team. In technical organizations, acknowledged writers often work on media and communications teams or as administrative support for senior managers. The work to produce documents, such as public-facing Web sites and brochures, is usually acknowledged as 
writing work and already tends to feature prominently in technical and professional writing courses at colleges and universities.

But writing work outside of these roles is often poorly understood and undervalued by staff, as was the case with the OAR reporting process at the supercomputing center before my research to document it. Not surprisingly, the less visible writing products and practices in industry and technical organizations do not tend to appear in most technical and professional writing courses or textbooks. My four-part framework affords technical communication practitioners or researchers in industry a methodology for documenting the less visible writing processes in order to improve understanding of them and better educate future technical professionals. While a theoretical framework cannot by itself promote broad pedagogical change, articulating and categorizing phenomena previously overlooked and undervalued provide a foundation for developing a more inclusive pedagogy and curriculum — and ultimately, a foundation for promoting a general cultural shift in what counts as writing.

\section{Conclusion}

What could be a more urgent or timely task for writing studies and technical communication than to make visible the boring, yet essential, things that constitute so much of organizational life yet are largely invisible to it? While writing is, after all, a "dominant form of labor" (Brandt, 2015) in the knowledge economy of the late $20^{\text {th }}$ century and early $21^{\text {st }}$ century, one of the longest standing mysteries of how writing is conceptualized by society at large is the persistence of the idea that what counts as writing must look something like a high-school English essay. This misconception about writing might be so pervasive because the high school or college essay is the only writing experience that most people have in common. So by the time knowledge workers have mastered the writing practices of their profession, they have sorted themselves into narrow disciplinary communities of scientists, engineers, bankers, and so on in 
which the writing practices of a successful professional are largely tacitly practiced, and few professionals identify the writing they do as the work of a writer. Then experts within a specialized discourse, professionals no longer have a reason or the broad perspective necessary to update their long-held personal theory of writing.

Bowker and Star (1999) recognized the difficulty in making visible the systems and practices that are built and maintained by specialists and largely unknown to the general user:

Information infrastructure is a tricky thing to analyze. Good, usable systems disappear almost by definition. The easier they are to use, the harder they are to see. As well, the bigger they are, the harder they are to see. Unless we are electricians or building inspectors, we rarely think about the myriad of databases, standards and instruction manuals subtending our reading lamps, much less about the politics of the electric grid that they tap into (p. 31).

In this quote, Bowker and Star pointed out that everyday users of electricity, whether they are wholly aware of it or not, turn the politics of the electric grid almost entirely over to the specialists in the discourse, such as electricians_-in part because the writing products and politics "subtending" such normal devises of everyday life (e.g., databases, standards, and instruction manuals) are largely unknown or accessible to anyone else. Somewhat surprisingly, these essential documents remain unknown even though they inscribe the controversies and politics that shape basic services, such delivering electricity to homes. Likewise, much of the writing done by professionals in technical organizations remains largely invisible and poorly understood, even though this technical and professional writing is essential to the organizations' mission, which often has a significant impact on public life. 
My point about the public's stake in making the invisible visible might seem like a diversion from my argument about the infrastructural function of writing. But it is less so when the risks attendant to these pervasive misconceptions about writing are fully taken into account. There are risks for society at large in refusing to acknowledge and understand how a more inclusive conception of what counts as writing and a broader idea of its functions make visible the structures and politics of organizations and bureaucracies in the public and private sectors. For example, where does the agency reside to author operational metrics against which the success of an organization, such as the publicly funded supercomputing center, will be evaluated, and what is the process for authoring them? Continuing to hold on to narrow conceptions about writing enables citizens to go on assuming that the normal writing processes and products of organizations and bureaucracies are, as Star said, free of controversy.

\section{Acknowledgments}

Thank you to Michael Michaud, Kristen Moore, and the blind peer reviewers for their generosity of time and attention in the development of this article. Thank you also to Michael A. Papka for his support of my research at Argonne Leadership Computing Facility.

\section{Author Biography}

Sarah Read is an assistant professor and director of Technical and Professional Writing at Portland State University. She was a guest faculty researcher at Argonne National Laboratory from 2014-2015. Her work has appeared in Technical Communication Quarterly, Journal of Business and Technical Communication, College Composition and Communication, the Journal of Writing Research and several edited collections. She teaches courses in the practice and theory of technical communication and writing studies and her research focuses on the ethnographic study of how texts mediate knowledge work in technical and professional settings. 


\section{References}

Adler-Kassner, L., \& Wardle, E. (Eds.). (2015). Naming what we know: Threshold concepts of writing studies. Louisville: University Press of Colorado.

Araujo, J., Matos, R., Alves, V., Maciel, P., Vieira de Souza, F.,Matias Jr., R., and Trivedi, K. S. (2014). Software aging in the Eucalyptus cloud computing infrastructure: Characterization and rejuvenation. ACM Journal on Emerging Technology in Computing Systems, 10,.1, Article 11, 22 pps. DOI: http://dx.doi.org/10.1145/2539122

Bazerman, C., \& Paradis, J. G. (Eds.). (1991). Textual dynamics of the professions: Historical and contemporary studies of writing in professional communities. Madison: University of Wisconsin Press.

Bawarshi, A. S., \& Reiff, M. J. (2010). Genre: An introduction to history, theory, research, and pedagogy. West Lafayette, IN: Parlor Press.

Berkenkotter, C. (2001). Genre systems at work: DSM-IV and rhetorical recontextualization in psychotherapy paperwork. Written Communication, 18, 326-349.

Bowker, G. (1994). Information mythology: The world as/of information. In L. Bud-Frierman (Ed.), Information acumen: The understanding and use of knowledge in modern business (pp. 231-247). London: Routledge.

Bowker, G. C., \& Star, S. L. (1999). Sorting things out: Classification and its consequences. Cambridge, MA: MIT Press.

Brandt, D. (2015). The rise of writing: Redefining mass literacy. Cambridge, UK: Cambridge University Press.

Buhr, W. (2003). What is infrastructure? Volkswirtschaftliche Diskussionsbeiträge (Research Report No. 107-03). Retrieved from Open Access Publication Server of the ZBW-Leibniz Information Centre for Economics Web site: https://www.zbw.eu/en/publish/. 
Bygstad, B. (2008). Information Infrastructure as organization: A critical realist view. Proceedings of the International Conference on Information Systems (ICIS), paper 190. http://aisel.aisnet.org/icis2008/190

Callon, M. (1986). Some elements of a sociology of translation: Domestication of the scallops and the fishermen of St. Brieuc Bay. In J. Law (Ed.), Power, action and belief: A new sociology of knowledge (pp. 196-233). London, UK: Routledge \& Kegan Paul.

Devitt, A. J. (1991). Intertextuality in tax accounting. In C. Bazerman \& J. G. Paradis (Eds.), Textual dynamics of the professions: Historical and contemporary studies of writing in professional communities (pp. 336-357). Madison: University of Wisconsin Press.

Dourish, P., \& Bell, G. (2011). Divining a digital future: Mess and mythology in ubiquitous computing. Cambridge, MA: MIT Press.

Freedman, A., \& Smart, G. (1997). Navigating the current of economic policy: Written genres and the distribution of cognitive work at a financial institution. Mind, Culture, and Activity, 4, 238-255.

Geertz, C. (1973). The interpretation of cultures (Vol. 5043). New York, NY: Basic Books.

Giddens, A. (1984). The constitution of society: Outline of the structuration theory. Cambridge, UK: Polity Press.

Grabill, J. T. (2007). Writing community change: Designing technologies for citizen action. New York, NY: Hampton Press.

Grabill, J. (2010). Infrastructure outreach and the engaged writing program. In S. K. Rose \& I. Weiser (Eds), Going public: What writing programs learn from engagement (pp. 15-28). Logan: Utah State University Press.

Hart-Davidson, W., Bernhardt, G., McLeod, M., Rife, M., \& Grabill, J. T. (2007). Coming to content management: Inventing infrastructure for organizational knowledge work. Technical Communication Quarterly, 17, 10-34. 
Heilker, P., \& Vandenberg, P. (Eds.). (2015). Keywords in Writing studies. Louisville, CO: University Press of Colorado.

Infrastructure (n.d.). In Merriam-Webster's Online dictionary. Retrieved from https://www.merriamwebster.com/dictionary/infrastructure

Joy, M., Muzykantskii, B., Rawles, S., \& Evans, M. (2002). An infrastructure for Web-based computerassisted learning. Journal on Educational Resources in Computing (JERIC), 2(4), 4.

Lampland, M., \& Star, S. L. (2009). Standards and their stories: How quantifying, classifying, and formalizing practices shape everyday life. Ithaca, NY: Cornell University Press.

Latour, B. (2011). Drawing things together. In M. Dodge, R. Kitchin \& C Perkins (Eds.) The map reader: Theories of mapping practice and cartographic representation, 65-72. Hoboken, NJ: Wiley Online Library.

Latour, B. (1995). Mixing humans and non-humans together: The sociology of a door closer. In S. L. Star (Ed.) Ecologies of knowledge: Work and politics in science and technology (pp. 257-279). Albany: SUNY Press.

Latour, B. (2005). Reassembling the social: An introduction to actor-network-theory. New York, NY: Oxford University Press.

Latour, B., \& Woolgar, S. (1986). Laboratory life: The construction of scientific facts. Princeton, NJ: Princeton University Press.

Law, J. (2002). Objects and spaces. Theory, Culture \& Society, 19, 91-105.

McCullough, M. (2004). On digital ground: Architecture, pervasive computing, and environmental knowing. Cambridge, MA: MIT Press.

Miller, C. R. (1984). Genre as social action. Quarterly Journal of Speech, 70, 151-167.

Miller, C. R. (2015). Genre as social action (1984), revisited 30 years later (2014). Letras \& Letras, 31(3), 56-72. 
Orlikowski, W. J., \& Yates, J. (1994). Genre repertoire: The structuring of communicative practices in organizations. Administrative Science Quarterly, 39, 541-574.

Paradis, J., Dobrin, D. N., \& Miller, R. (1985). Writing at Exxon ITD: Notes on the writing environment of an R\&D organization. In L. Odell \& D. Goswami (Eds.), Writing in nonacademic settings (pp. 281-307). New York: Guilford Press.

Read, S. (2015). Making a thing of quality childcare: Latourian rhetoric doing things. In P. Lynch \& N. Rivers (Eds.), Thinking with Bruno Latour in rhetoric and composition (pp. 256-293). Carbondale: Southern Illinois University Press.

Read, S. (2016). The net work genre function. Journal of Business and Technical Communication, 30, 419-450.

Read, S. (2018). Writing down the machine: Enacting Latourian ethnography to trace how a supercomputer circulates the halls of Washington, DC as a report. In K. Moore \& D. Richards, (Eds.), Posthuman Praxis in Technical Communication (pp. 141-159). New York \& London, UK: Routledge.

Read, S. and Papka M. (2014). Genre Cycling: The infrastructural function of an operational assessment review and reporting process at a federal scientific supercomputing user facility. Proceedings of the 32nd ACM International Conference on the Design of Communication (pp. 1-8). New York: ACM.

Read, S. and Michael P. (2016). Improving models of document cycling: Accounting for the less visible writing activities of an annual reporting process at a supercomputing facility. Proceedings of the 2016 IEEE International Professional Communication Conference (pp. 1-10). New York: IEEE.

Read, S., \& J. Swarts (2015). Visualizing and tracing: Research methodologies for distributed, networked, sociotechnical activity, otherwise known as knowledge work. Technical Communication Quarterly, 24, 14-44. 10.1080/10572252.2015.975961 
Rouse, Margaret (n.d.). Definition: Infrastructure (IT infrastructure). Retrieved from http://searchdatacenter.techtarget.com/definition/infrastructure.

Smart, G. (2006). Writing the economy: Activity, genre and technology in the world of banking. Sheffield, England: Equinox.

Spinuzzi, C. (2002). Modeling genre ecologies. Proceedings of the 20th Annual ACM International Conference on Design of Communication (pp. 200-207). New York, NY: ACM.

Spinuzzi, C. (2003). Tracing genres through organizations: A sociocultural approach to information design. Cambridge, MA: MIT Press.

Spinuzzi, C. (2004). Four ways to investigate assemblages of texts: Genre sets, systems, repertoires, and ecologies. Proceedings of the 22th Annual International Conference on Design of Communication (pp. 110-116). New York, NY: ACM.

Spinuzzi, C. (2008). Network: Theorizing knowledge work in telecommunications. Cambridge, UK: Cambridge University Press.

Spinuzzi, C. (2010). Secret sauce and snake oil: Writing monthly reports in a highly contingent environment. Written Communication, 27, 363-409.

Star, S. L. (Ed.). (1995). Ecologies of knowledge: Work and politics in science and technology. Albany: SUNY Press.

Star, S. L. (1999). The ethnography of infrastructure. American behavioral scientist, 43, 377-391.

Star, S. L., \& K. Ruhleder, 1996. Steps toward an ecology of infrastructure: Design and access for large information spaces. Information Systems Research, 7, 111-113.

Swarts, J. 2010. Recycled writing: Assembling actor networks from reusable content. Journal of Business and Technical Communication, 24, 127-163.

Vee, A. (2013). Understanding computer programming as a literacy. Literacy in Composition Studies, $1(2), 42-64$. 
Winsor, D. A. (1990). Engineering writing = writing engineering. College Composition and Communication, 41(1), 58-70.

Winsor, D. A. (1992). What counts as writing? An argument from engineers' practice. Journal of Advanced Composition, 12, 337-347.

Winsor, D. A. (1994). Invention and writing in technical work: Representing the object. Written Communication, 11, 227-250. doi: 10.1177=0741088394011002003

Winsor, D. A. (1999). Genre and activity systems: The role of documentation in maintaining and changing engineering activity systems. Written Communication, 16, 200-224.

Winsor, D. A. (2003). Writing power: Communication in an engineering center. Albany: State University of New York Press.

Yates, J., \& Orlikowski. W. (2002). Genre systems: Structuring interaction through communicative norms. Journal of Business Communication, 39, 13-35. 